\title{
Helicobacter pylori Mutations Conferring Resistance to Fluoroquinolones and Clarithromycin among Dyspeptic Patients Attending a Tertiary Hospital, Tanzania
}

\author{
Hyasinta Jaka $\mathbb{D}^{1},{ }^{1}$ Nele Rüttgerodt, ${ }^{2}$ Wolfgang Bohne, ${ }^{3}$ Andreas Mueller, ${ }^{2}$ Uwe Gross, ${ }^{3}$ \\ Christa Kasang, ${ }^{4}$ and Stephen E. Mshana ${ }^{5}$ \\ ${ }^{1}$ Department of Internal Medicine, Gastroenterology and Hepatology Unit, Catholic University of Health and Allied Sciences, \\ P.O. Box 1464, Bugando, Mwanza, Tanzania \\ ${ }^{2}$ Tropenmedizin, Missionsärztliche Klinik, Salvatorstr. 7, 97074 Würzburg, Germany \\ ${ }^{3}$ Medical Microbiology, Goettingen, Germany \\ ${ }^{4}$ Medical Mission Institute, Hermann Schell Str. 7, 97074 Würzburg, Germany \\ ${ }^{5}$ Department of Microbiology and Immunology, Catholic University of Health and Allied Sciences, \\ P.O. Box 1464, Bugando, Mwanza, Tanzania \\ Correspondence should be addressed to Hyasinta Jaka; yasintaliwa5@gmail.com
}

Received 7 January 2019; Revised 6 May 2019; Accepted 19 June 2019; Published 1 July 2019

Academic Editor: Maikel P. Peppelenbosch

Copyright (C) 2019 Hyasinta Jaka et al. This is an open access article distributed under the Creative Commons Attribution License, which permits unrestricted use, distribution, and reproduction in any medium, provided the original work is properly cited.

Objectives. Helicobacter pylori (H. pylori) isolates resistant to clarithromycin and quinolones are increasing worldwide. Data regarding the magnitude of $H$. pylori resistance are limited in developing countries. Here, we report the prevalence of mutations conferring resistance to clarithromycin and fluoroquinolones among dyspeptic patients attending a tertiary hospital, Tanzania. Methods. Between August 2014 and August 2016, patients undergoing upper gastrointestinal endoscopy at the Bugando Medical Centre were enrolled. Biopsies were taken for polymerase chain reaction (PCR) and sequencing to detect mutations conferring resistance to clarithromycin and fluoroquinolones. Results. A total of 208 nonrepetitive biopsies were examined of which 188 ( $90.4 \%$ ) tested positive for $H$. pylori specific $23 \mathrm{~S}$ rRNA PCR. Clarithromycin resistance mutations were detected in 54/188 (28.7\%) of patients tested. The most frequently detected mutation was A2143G (30) followed by A2142G (20). Out of 131 nonrepetitive biopsies tested for fluoroquinolones resistance mutations, 77/131 (58.8\%) were positive, with N87I (20) mutation being the most frequently detected mutation followed by A92T mutation which was detected in 16 samples. Conclusion. A significant proportion of dyspeptic patients attending tertiary hospital in Tanzania are infected with $\mathrm{H}$. pylori strains harbouring clarithromycin or fluoroquinolones resistance mutations. Detection of more than $50 \%$ of strains with fluoroquinolones resistance mutations makes the $H$. pylori second line treatment questionable in our setting. There is a need of surveillance of $H$. pylori resistance patterns in Tanzania to provide data that can guide empirical treatment to reduce associated morbidity of $H$. pylori infections. The correlation between A92T fluoroquinolone mutation and phenotypic resistance requires further investigations.

\section{Introduction}

$H$. pylori is a gram negative bacterium, spiral shaped, microaerophilic, and motile with polar flagella, belonging to the genus Helicobacter. H. pylori can lead to gastritis, peptic ulcer diseases, and gastric cancers [1]. Invasive and noninvasive tests can be used to diagnose $H$. pylori infection; however, culture and molecular tests are methods which can detect the presence of organism as well as the resistance patterns of the H. pylori strains [2]. Polymerase chain reaction (PCR), which selectively amplifies the target gene, is a quick, highly sensitive, and specific test to diagnose H. pylori infections [3]. In developing countries, culture and molecular methods are not routinely done. Molecular method is among the methods used for the detection of $H$. pylori and determination of mutation which confers antimicrobial resistance even at a concentration so low that could not be detected by the culture [4]. 
H. pylori infection can complicate the chronic atrophic gastritis which is the precancerous stage to adenocarcinoma $[5,6]$. In the recent published global cancer statistics, gastric cancer was ranked third for cancer-related mortality worldwide and fifth for incidence [7]. H. pylori eradication prevents and slows down the progression of nonatrophic chronic gastritis to atrophic gastritis, hence reducing gastric cancer risk [8]. Therefore, early treatment of patients with $H$. pylori may decrease gastric cancer incidence and its associated mortality [8].

The treatment of $H$. pylori consists of triple therapy (PPI + clarithromycin + either amoxicillin or metronidazole) which can be used in areas with known low clarithromycin resistance, while nonbismuth quadruple concomitant regimen (a proton pump inhibitor, amoxicillin, metronidazole, and clarithromycin) is recommended as first line together with bismuth quadruple therapy (PPI + bismuth + metronidazole + tetracycline) in areas of high clarithromycin resistance [9-11]. Efficacy of these regimens is compromised by drug resistance which is increasing in Africa [12].

Clarithromycin resistance in the first line triple therapy regimens is the main cause of $H$. pylori eradication failure $[13,14]$. In the H. pylori treatment, clarithromycin is one of the important drugs in the standard therapy of $H$. pylori, while the quinolone is the key drug in the second line therapy [15]. Worldwide, the prevalence of clarithromycin and fluoroquinolone resistance is $19.74 \%$ and $18.94 \%$, respectively while in Africa the prevalence of clarithromycin has been found to range from $0 \%$ to $100 \%$ and that of fluoroquinolones from $0 \%$ to $32 \%[12,16]$.

Several mutations have been detected at peptidyl transferase-encoding region in $\mathrm{V}$ domain of the $H$. pylori $23 \mathrm{~S}$ rRNA, which is a component of the large subunit (50S) of the bacterial ribosome. This domain is the most common binding site for antibiotics that inhibit translation like clarithromycin. Therefore, 23SrRNA is used to diagnose $H$. pylori and at the same time detect antibiotic resistance (mutations associated with antibiotic resistance). Most of the known point mutations are $A$ to $G$ transition mutations $[17,18]$ but three point mutations, namely, A2142G, A2143G, and A2142C, are responsible for $90 \%$ of primary clarithromycin resistance in $H$. pylori [19]. In the presence of clarithromycin resistance, eradication failure occurs in about $44.5 \%$ to $82 \%$ of cases [19]. Second line regimen includes quinolone based therapy which is alternative after failure of first line regimen. Quinolone resistance to $H$. pylori has been associated with second line treatment failure in $27 \%$ of patients [20]. A mutation in the quinolone-resistance-determining region (QRDR) is responsible for the resistance to quinolones. Mutations which have been found to cause quinolones resistance include N87H, N87I, N87K, N87Y, D91A, D91G, D91N, and D91Y $[12,21,22]$. The N87 mutations are the key determinants in the failure of quinolones-containing regimen [23].

In Tanzania, most of the first line regimens include clarithromycin while second line regimens are based on quinolones. Despite the high prevalence of $H$. pylori gastroduodenal diseases in Tanzania and the observed high rate of treatment failure, the $H$. pylori mutations conferring resistance to antibiotics have never been studied. Therefore, for the first time in Tanzania, this study has documented the magnitude of $H$. pylori mutations conferring resistance to clarithromycin and fluoroquinolones among dyspeptic patients attending tertiary hospital. These data are highly needed in order to review empirical treatment of $H$. pylori in our setting.

\section{Materials and Methods}

2.1. Study Design and Study Population. This was a crosssection study among dyspeptic patients undergoing upper gastrointestinal (GI) endoscopy at the endoscopy unit of the Bugando Medical Centre, from August 2014 to August 2016. All adult dyspeptic patients referred for upper GI endoscopy as part of their workup for their dyspeptic symptoms with no history of antibiotic treatment for $H$. pylori within the past 30 days were included in the study. Dyspepsia was defined according to the ROME criteria [24]. During the upper GI endoscope procedure from one patient, two biopsies were taken from both antrum and fundus. Biopsies for every patient were stored in a single container with $70 \%$ ethanol. A total of 208 tissue samples were obtained from 208 patients.

\subsection{DNA Extraction, Amplification, and Sequencing of the Clarithromycin and Quinolone Resistance-Determining Regions}

DNA Purification from Tissues. Two biopsies (antrum and fundus) were ground using a tissue homogenizer (UltraTurax; Labo-Moderne, Paris, France). The genomic DNA was extracted using a QIAamp DNA minitissue extraction (Qiagen SA, Courtaboeuf, France) according to the manufacturer's instructions [25].

$H$. pylori detection and clarithromycin mutations: amplification of a $267 \mathrm{bp}$ fragment of the H. pylori 23S rRNA was performed by Real-Time PCR (Light Cycler- Roche) using oligonucleotides HPY-S: 5-AGGTTAAGAGGATGCGTCAGTC and HPY-A: 5-CGCATGATATTCCCATTAGCAGT (GenBank accession no. U27270) as previously described [26]. The PCR was carried out in $15 \mu$ l volume containing Ampli Taq DNA polymerase 1U, PCR buffer 1X, deoxynucleoside triphosphate (dNTP) $200 \mu \mathrm{M}, \mathrm{PCR}$ water $7 \mu \mathrm{l}$, and $0.2 \mu \mathrm{M}$ of each of the primers [26]. After an initial denaturation step at $95^{\circ} \mathrm{C}$ for 10 minutes, 40 PCR cycles were performed with $95^{\circ} \mathrm{C}$ for 10 seconds (denaturation), $60^{\circ} \mathrm{C}$ for 10 seconds (annealing), and $72^{\circ} \mathrm{C}$ for 20 seconds (extension). Melting curve analysis was performed for each sample. PCR products were purified using the Qiagen PCR-purification kit [25] and sequenced (Seqlab, Göttingen). Mutations within the $23 \mathrm{~S}$ gene were detected by DNA sequence alignment with the wild type allele using the Geneious software package [version 8.0.4 available from www.geneious.com (Biomatters, Ltd.)].

GyrA Genes Amplification for Fluoroquinolones Mutations. Using oligonucleotides GyrA-1 (TTAGCTTATTCAATGAGCGT) and GyrA-2 (GCAGACGGCTTGGTAGAATA), a 428 bp GyrA fragment was amplified from genomic DNA by Real-Time PCR (Light Cycler, Roche) as previously described 
TABLE 1: Patterns of mutations among 54 patients/samples with point mutations.

\begin{tabular}{|c|c|c|c|c|c|}
\hline Antibiotic tested & Tested samples & Mutation type & $\begin{array}{l}\text { All point } \\
\text { mutations } \\
\text { identified }\end{array}$ & $\begin{array}{c}\text { Heterozygote } H . \\
\text { pylori } \\
\text { strains }\end{array}$ & $\begin{array}{c}\text { Homozygote } \\
\text { H. pylori } \\
\text { strains }\end{array}$ \\
\hline \multirow{5}{*}{ Clarithromycin } & \multirow{5}{*}{188} & A2143G & $30 / 54$ & $13 / 30$ & $17 / 30$ \\
\hline & & A2142G & $20 / 54$ & $14 / 20$ & $6 / 20$ \\
\hline & & A2142C & $1 / 54$ & 0 & 1 \\
\hline & & A2143C & $1 / 54$ & 0 & 1 \\
\hline & & $\mathrm{A} 2143 \mathrm{G}+\mathrm{A} 2142 \mathrm{G}$ & $2 / 54$ & $1 / 2$ & $1 / 2$ \\
\hline
\end{tabular}

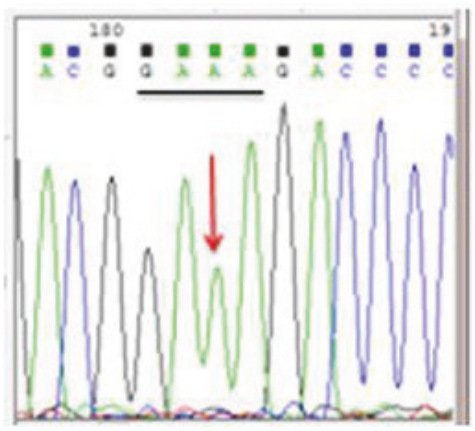

(a)

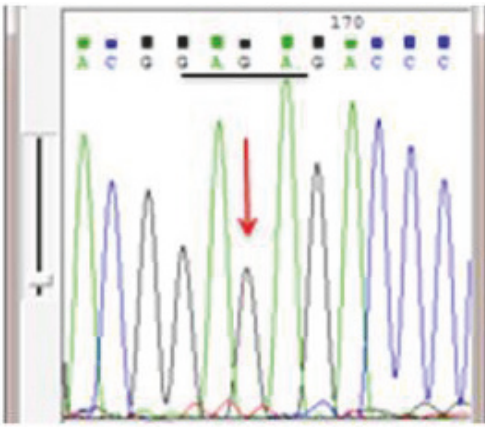

(b)

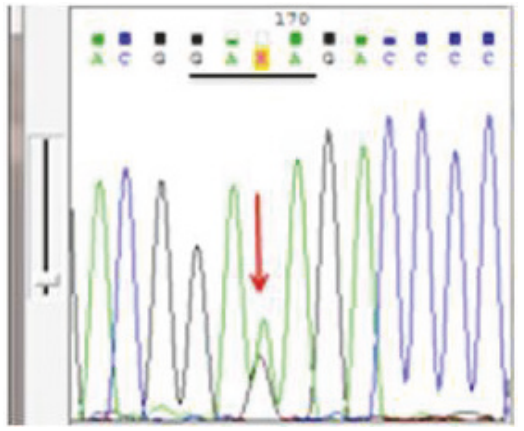

(c)

Figure 1

[27]. The PCR was carried out in $20 \mu l$ volume containing $4 \mu$ (Ampli Taq DNA polymerase 1U, PCR buffer 1X, deoxynucleoside triphosphate (dNTP) $200 \mu \mathrm{M}), 5 \mu \mathrm{l}$ DNA, $7 \mu \mathrm{l} \mathrm{H}_{2} \mathrm{O}$, and $2 \mu \mathrm{l}$ of each primer $(5 \mu \mathrm{M})$. After an initial denaturation step at $95^{\circ} \mathrm{C}$ for 10 minutes, 40 PCR cycles were performed with $95^{\circ} \mathrm{C}$ for 10 seconds (denaturation), $55^{\circ} \mathrm{C}$ for 10 seconds (annealing), and $72^{\circ} \mathrm{C}$ for 20 seconds (extension). PCR products were purified using the Qiagen PCR-purification kit [25] and subjected to DNA sequencing (Seqlab, Göttingen). Mutations within the quinolone resistance-determining region (QRDR) of the H. pylori GyrA gene (GenBank accession no. AE000583) [28] were detected by DNA sequence alignment with the wild type allele using the Geneious software package [version 8.0.4 available from www.geneious.com (Biomatters, Ltd.)].

This molecular work was done in the Department of Medical Microbiology, University of Gottingen, Germany. Data were entered in Excel sheet and summarized using percentages. The total numbers of samples tested for clarithromycin and fluoroquinolones mutations were used as denominators.

\section{Results}

Out of 208 biopsies from nonrepetitive patients examined for $H$. pylori by PCR method, 188/208 (92.2\%) were PCR positive. Mutations conferring resistance to clarithromycin were detected in 54/188 (28.7\%) of patients. The mutations detected were A2143G (30) \{Figure 1\}, A2142G (20), A2142C (1), and A2143C (1). Two samples had double mutations A2142G + A2143G and 22/188 (11.7\%) samples had both wild type and mutants (Table 1 ).
On the other hand, out of 188 patients with positive $H$. pylori PCR, 131 (69.7\%) were analyzed for gyrA mutations that are known to confer fluoroquinolones resistance. Fluoroquinolone resistance mutations were detected in $77 / 131$ (58.8\%) samples; these included N87I (20) \{Figure 2\}, N87K (7), D91G (8), D91N (15), D91Y (11), and A92T (20.8\%) Table 2 . Nine (11.7\%) samples out of 77 had both wild type and mutants or had heterozygote $H$. pylori strains (Table 2 ).

A total of $20 / 77$ (25.9\%) who had mutation in gyrA gene had also point mutation in $H$. pylori $23 \mathrm{~S}$ rRNA gene implying that $20 / 54(37 \%)$ of samples with clarithromycin mutations had also quinolones mutations.

\section{Discussion}

Worldwide, the prevalence of primary $H$. pylori resistant to clarithromycin is $19.4 \%$ [16]. In European countries, a high prevalence has been reported, ranging from $12.5 \%$ to $23.5 \%$ [19], while in Africa the overall clarithromycin resistance was $29.2 \%$ [12]. In our study, we have observed the presence of clarithromycin mutations that predict drug resistance in $28.7 \%$ of patients who were not on eradication therapy. These findings are in line with other studies $[12,29,30]$. However, the observed prevalence of clarithromycin mutations is low compared to the prevalence found in certain parts of Asia (Ina and Vietnam), whereby the prevalence of $43 \%$ and that of $85.5 \%$, respectively, were observed $[31,32]$, and it is higher compared to study done in Congo Brazzaville [33]. The high prevalence of clarithromycin mutations in developing countries could be linked to the overuse of macrolides for treatment of diarrheal diseases in developing countries [34]. 


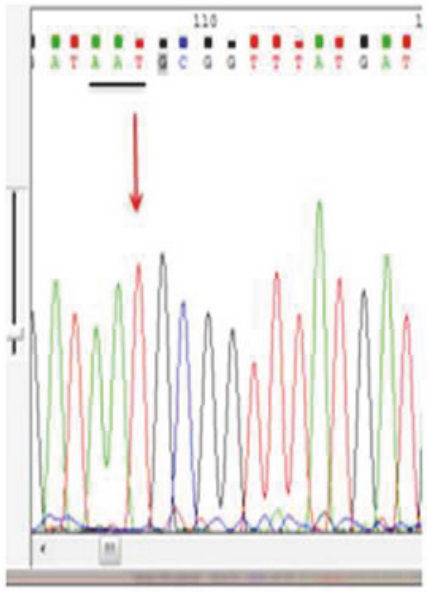

(a)

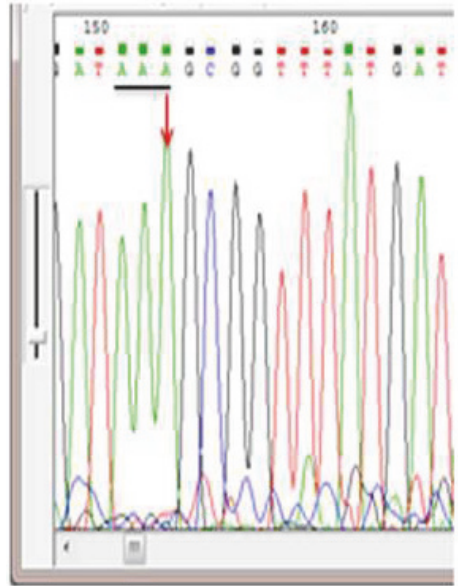

(b)

Figure 2

TABLE 2: Patterns of mutation among 77 patients/samples with point mutations.

\begin{tabular}{|c|c|c|c|c|c|}
\hline Antibiotic tested & Tested samples & Mutation type & $\begin{array}{c}\text { All point } \\
\text { mutations } \\
\text { identified }\end{array}$ & $\begin{array}{c}\text { Heterozygote } H . \\
\text { pylori } \\
\text { strains }\end{array}$ & $\begin{array}{c}\text { Homozygote } \\
\text { H. pylori } \\
\text { strains }\end{array}$ \\
\hline \multirow{6}{*}{ Fluoroquinolones } & \multirow{6}{*}{131} & N87I & 20 & $5 / 20$ & $15 / 20$ \\
\hline & & N87K & 7 & $3 / 7$ & $4 / 7$ \\
\hline & & D91G & 8 & $2 / 8$ & $6 / 8$ \\
\hline & & D91N & 15 & $1 / 15$ & $14 / 15$ \\
\hline & & D91Y & 11 & $1 / 11$ & $10 / 11$ \\
\hline & & A92T* & 16 & $2 / 16$ & $14 / 16$ \\
\hline
\end{tabular}

* Unknown mutation

In $23 \mathrm{~S}$ rRNA gene, most of the known point mutations conferring resistance to clarithromycin are A to $G$ transition mutations [18]. Of these, three point mutations, namely, A2142G, A2143G, and A2142C, are responsible for $90 \%$ of primary clarithromycin resistance in $H$. pylori [19]. This was confirmed in the present study, whereby A2143G, A2142G, and $\mathrm{A} 2142 \mathrm{C}$ formed the majority of clarithromycin mutations detected $[17,19,35,36]$. It should be noted that the observed mutations have different therapeutic outcome; the presence of A2143G significantly reduced the eradication rate of the H. pylori compared to other mutations [36, 37]. Of note, clarithromycin resistance mutations detected in this cohort significantly predicted treatment failure as documented in our previous publication [38]. In areas with high prevalence of clarithromycin resistance of $>15 \%$, the recommended regimens are the Bismuth quadruple therapy and concomitant therapy for 14 days according to the Canadian guidelines and 10 days according to the North American and European guidelines $[9,11,15]$. Other mutations which can be found in other parts of the world which have been found to confer clarithromycin resistance in $H$ pylori strains are the T2289C, T2190C, T2182C, A2223G, C2195T, C2245T, C2694A, G2141A and G2224A, A2146C, A2146G, and A2147G [39-42].

Regarding fluoroquinolones resistance rates, 3.9\% prevalence has been reported in Europe and $17.4 \%$ in Africa
[43]. The highest rate in Africa has been reported in Congo Brazzaville [12, 33, 44]; however in the current study, about $59 \%$ of patients studied carried known fluoroquinolones resistance mutations. Quinolone resistance to $H$. pylori has been associated with second line treatment failure [20]; therefore these findings are alarming because a significant proportion of patients on the second line regimen might have treatment failure. This could be explained by the fact that in Tanzania quinolones are commonly used in the treatment of urinary tract infections, typhoid fever, infectious diarrhea, and genital discharge syndrome, hence selecting for $H$. pylori resistant strains. The alternative for treatment of $H$. pylori for the patients who fail second line is bismuth quadruple therapy [45] which is not commonly available in lower health facilities.

The main fluoroquinolones resistance mutations have been detected in gyrA gene at the codon positions 87, 88, 91, and $97[46,47]$. As in other studies, in the current study the commonest mutations were in gyr87 [12]. In our study, the mutation A92T in the gyrA gene was detected for the first time in $H$. pylori. This mutation has been reported in Neisseria gonorrhea [48]. In that study, the resistant isolates to gepotidacin (topoisomerase type II inhibitor) were found to have an additional A92T mutation. In our study, other mutations which have been identified in other parts of the 
world were not detected; these mutations include $\mathrm{N} 87 \mathrm{H}$, N87Y, and D91A. This could be explained by the fact that the distribution of mutations depends on the phylogeographic tree differences of $H$. pylori due to gene content diversity which can be due to either gene loss or gene recombination in multiple strains [49].

\section{Conclusion}

A significant proportion of dyspeptic patients attending tertiary hospital in Tanzania are infected with $H$. pylori strains harboring clarithromycin or fluoroquinolones resistance mutations. Detection of more than $50 \%$ of strains with fluoroquinolones resistance mutations makes the $H$. pylori second line treatment questionable in our setting. There is a need of surveillance of $H$. pylori resistance patterns in Tanzania to provide data that can guide empirical treatment to reduce associated morbidity and mortality of $H$. pylori infections. The correlation between A92T fluoroquinolone mutation and phenotypic resistance in $H$. pylori requires further investigations

\section{Data Availability}

The data belongs to the CUHAS University and Bugando Hospital; a permission is required to make them freely available.

\section{Additional Points}

Highlights. (i) $90 \%$ PCR positive for $H$. pylori. (ii) High prevalence of gyrA mutations. (iii) High frequency of A2142G and N87I. (iv) A92T unknown mutation in gyrA gene.

\section{Ethical Approval}

This study was approved by the Ethics and Research Committee of CUHAS/Bugando with an updated clearance for publication number CREC/066b/2015.

\section{Consent}

During and after study period, informed consent form was filled by all patients and all information collected was kept strictly confidential.

\section{Conflicts of Interest}

There are no conflicts of interest to declare.

\section{Authors' Contributions}

All authors have made substantial contributions: Hyasinta Jaka, Nele Rüttgerodt, and Stephen E. Mshana did the conception and design of the study, analysis and interpretation of data, and drafting of the article. Hyasinta Jaka, Nele Rüttgerodt, Uwe Gross, and Wolfgang Bohne did the acquisition of data, laboratory work, and clinical work.
Hyasinta Jaka, Andreas Mueller, Christa Kasang, and Stephen E. Mshana did the analysis of data and drafting of article and revised it critically for important intellectual content while Christa Kasang and Stephen E. Mshana approved the final version to be submited.

\section{Acknowledgments}

We would like to thank Dr. Sarah W. Matuja and all nurses at the Bugando endoscopy unit for assisting us with the patient enrolment. This study is part of Ph.D. work, which was funded by triangular partnership between Stellenbosch South Africa, Mission Institute Würzburg in Germany, and the Catholic University of Health and Allied Sciences, Bugando, Tanzania.

\section{References}

[1] M. N. Weck and H. Brenner, "Prevalence of chronic atrophic gastritis in different parts of the world," Cancer Epidemiology, Biomarkers \& Prevention, vol. 15, no. 6, pp. 1083-1094, 2006.

[2] F. Mégraud and P. Lehours, "Helicobacter pylori detection and antimicrobial susceptibility testing," Clinical Microbiology Reviews, vol. 20, no. 2, pp. 280-322, 2007.

[3] C. L. Clayton, H. Kleanthous, P. J. Coates, D. D. Morgan, and S. Tabaqchali, "Sensitive detection of Helicobacter pylori by using polymerase chain reaction," Journal of Clinical Microbiology, vol. 30, no. 1, pp. 192-200, 1992.

[4] M. Oleastro, A. Menard, A. Santos et al., "Real-Time PCR assay for rapid and accurate detection of point mutations conferring resistance to clarithromycin in helicobacter pylori," Journal of Clinical Microbiology, vol. 41, no. 1, pp. 397-402, 2003.

[5] M. Rugge, R. M. Genta, F. Di Mario et al., "Gastric cancer as preventable disease," Clinical Gastroenterology and Hepatology, vol. 15, no. 12, pp. 1833-1843, 2017.

[6] M. C. Mommersteeg, J. Yu, M. P. Peppelenbosch, and G. M. Fuhler, "Genetic host factors in Helicobacter pylori-induced carcinogenesis: Emerging new paradigms," Biochimica et Biophysica Acta (BBA) - Reviews on Cancer, vol. 1869, no. 1, pp. 4252, 2018.

[7] F. Bray, J. Ferlay, I. Soerjomataram, R. L. Siegel, L. A. Torre, and A. Jemal, "Global cancer statistics 2018: GLOBOCAN estimates of incidence and mortality worldwide for 36 cancers in 185 countries," CA: A Cancer Journal for Clinicians, vol. 68, no. 6, pp. 394-424, 2018.

[8] P. Pimentel-Nunes, D. Libânio, R. Marcos-Pinto et al., "Management of epithelial precancerous conditions and lesions in the stomach (MAPS II): European Society of Gastrointestinal Endoscopy (ESGE), European Helicobacter and Microbiota Study Group (EHMSG), European Society of Pathology (ESP), and Sociedade Portuguesa de Endoscopia Digestiva (SPED) guideline," Endoscopy, vol. 51, no. 04, pp. 365-388, 2019.

[9] C. A. Fallone, N. Chiba, S. V. van Zanten et al., "The toronto consensus for the treatment of helicobacter pylori infection in adults," Gastroenterology, vol. 151, no. 1, pp. 51-69.e14, 2016.

[10] J. P. Gisbert, J. Molina-Infante, J. Amador et al., "IV Spanish Consensus Conference on Helicobacter pylori infection treatment," Gastroenterología y Hepatología (English Edition), vol. 39, no. 10, pp. 697-721, 2016. 
[11] P. Malfertheiner, F. Megraud, C. O'morain et al., "Management of Helicobacter pylori infection-the Maastricht V/Florence consensus report," Gut, vol. 66, no. 1, pp. 6-30, 2017.

[12] H. Jaka, J. A. Rhee, L. Östlundh et al., "The magnitude of antibiotic resistance to Helicobacter pylori in Africa and identified mutations which confer resistance to antibiotics: Systematic review and meta-analysis," BMC Infectious Diseases, vol. 18, no. $1,2018$.

[13] D. Y. Graham, G. M. Lew, H. M. Malaty et al., "Factors influencing the eradication of Helicobacter pylori with triple therapy," Gastroenterology, vol. 102, no. 2, pp. 493-496, 1992.

[14] H. Jaka, A. Mueller, C. Kasang, and S. E. Mshana, "Predictors of triple therapy treatment failure among H. pylori infected patients attending at a tertiary hospital in Northwest Tanzania: a prospective study," BMC Infectious Diseases, vol. 19, no. 1, 2019.

[15] W. D. Chey, G. I. Leontiadis, C. W. Howden, and S. F. Moss, "ACG Clinical Guideline: Treatment of Helicobacter pylori Infection," American Journal of Gastroenterology, vol. 112, no. 2, pp. 212-239, 2017.

[16] R. Ghotaslou, H. E. Leylabadlo, and Y. M. Asl, "Prevalence of antibiotic resistance in Helicobacter pylori: A recent literature review," World Journal of Methodology, vol. 5, no. 3, p. 164, 2015.

[17] G. Wang and D. E. Taylor, "Site-specific mutations in the $23 \mathrm{~S}$ rRNA gene of Helicobacter pylori confer two types of resistance to macrolide-lincosamide-streptogramin B antibiotics," Antimicrobial Agents and Chemotherapy, vol. 42, no. 8, pp. 1952-1958, 1998.

[18] S. Hellmig, J. Hampe, and S. Schreiber, "Helicobacter pylori infection in Africa and Europe: enigma of host genetics," Gut, vol. 52, no. 12, p. 1799, 2003.

[19] F. Giorgio, M. Principi, V. De Francesco et al., "Primary clarithromycin resistance to Helicobacter pylori: is this the main reason for triple therapy failure?" World Journal of Gastrointestinal Pathophysiology, vol. 4, no. 3, pp. 43-46, 2013.

[20] F. Silva, E. Queiroz, T. Navarro-Rodriguez et al., "Efficacy of levofloxacin, amoxicillin and a proton pump inhibitor in the eradication of Helicobacter pylori in Brazilian patients with peptic ulcers," Clinics, vol. 70, no. 5, pp. 318-321, 2015.

[21] K.-H. Hung, B.-S. Sheu, W.-L. Chang, H.-M. Wu, C.-C. Liu, and J.-J. Wu, "Prevalence of primary fluoroquinolone resistance among clinical isolates of Helicobacter pylori at a University Hospital in Southern Taiwan," Helicobacter, vol. 14, no. 1, pp. 6165, 2009.

[22] G. Wang, T. J. Wilson, Q. Jiang, and D. E. Taylor, "Spontaneous mutations that confer antibiotic resistance in helicobacter pylori," Antimicrobial Agents and Chemotherapy, vol. 45, no. 3, pp. 727-733, 2001.

[23] T. N. Phan, A. Santona, V. H. Tran et al., "High rate of levofloxacin resistance in a background of clarithromycinand metronidazole-resistant Helicobacter pylori in Vietnam," International Journal of Antimicrobial Agents, vol. 45, no. 3, pp. 244-248, 2015.

[24] J. Tack and N. J. Talley, "Functional dyspepsia-symptoms, definitions and validity of the Rome III criteria," Nature Reviews Gastroenterology \& Hepatology, vol. 10, no. 3, pp. 134-141, 2013.

[25] Qiagen, QIAamp ${ }^{\circledR}$ DNA Mini and Blood Mini Handbook, vol. 3, 2012.

[26] A. Menard, A. Santos, F. Megraud, and M. Oleastro, "PCRrestriction fragment length polymorphism can also detect point mutation $\mathrm{A} 2142 \mathrm{C}$ in the $23 \mathrm{~S}$ rRNA gene, associated with helicobacter pylori resistance to clarithromycin," Antimicrobial Agents and Chemotherapy, vol. 46, no. 4, pp. 1156-1157, 2002.
[27] C. Kao, A. Lee, A. Huang et al., "Heteroresistance of Helicobacter pylori from the same patient prior to antibiotic treatment," Infection, Genetics and Evolution, vol. 23, pp. 196-202, 2014.

[28] E. Glocker and M. Kist, "Rapid detection of point mutations in the gyrA gene of helicobacter pylori conferring resistance to ciprofloxacin by a fluorescence resonance energy transfer-based real-time PCR approach," Journal of Clinical Microbiology, vol. 42, no. 5, pp. 2241-2246, 2004.

[29] N. Bouihat, C. Burucoa, A. Benkirane et al., "Helicobacter pylori primary antibiotic resistance in 2015 in Morocco: a phenotypic and genotypic prospective and multicenter study," Microbial Drug Resistance, vol. 23, no. 6, pp. 727-732, 2017.

[30] J. Y. Park, K. B. Dunbar, M. Mitui et al., "Helicobacter pylori clarithromycin resistance and treatment failure are common in the USA," Digestive Diseases and Sciences, vol. 61, no. 8, pp. 2373-2380, 2016.

[31] M. Goudarzi, M. Heidary, M. Azad, M. Fazeli, and H. Goudarzi, "Evaluation of antimicrobial susceptibility and integron carriage in Helicobacter pylori isolates from patients," Gastroenterology and Hepatology from Bed to Bench, vol. 9, pp. S47-S52, 2016.

[32] C. Quek, S. T. Pham, K. T. Tran et al., "Antimicrobial susceptibility and clarithromycin resistance patterns of Helicobacter pylori clinical isolates in Vietnam," F1000Research, vol. 5, 2016.

[33] E. N. O. Ngoyi, B. I. A. Ibara, R. Moyen et al., "Molecular detection of Helicobacter pylori and its antimicrobial resistance in Brazzaville, Congo," Helicobacter, vol. 20, no. 4, pp. 316-320, 2015.

[34] F. Megraud, S. Coenen, A. Versporten et al., "Helicobacter pylori resistance to antibiotics in Europe and its relationship to antibiotic consumption," Gut, vol. 62, no. 1, pp. 34-42, 2013.

[35] M. Pina, A. Occhialini, L. Monteiro, H.-P. Doermann, and F. Mégraud, "Detection of point mutations associated with resistance of Helicobacter pylori to clarithromycin by hybridization in liquid phase," Journal of Clinical Microbiology, vol. 36, no. 11, pp. 3285-3290, 1998.

[36] V. De Francesco, M. Margiotta, A. Zullo et al., "Clarithromycinresistant genotypes and eradication of Helicobacter pylori," Annals of Internal Medicine, vol. 144, no. 2, pp. 94-100, 2006.

[37] V. De Francesco, A. Zullo, E. Ierardi et al., "The A2143G point mutation of clarithromycin resistance affects helicobacter pylori eradication," Journal of Clinical Gastroenterology, vol. 43, no. 4, p. 386, 2009.

[38] H. Jaka, C. Kasang, A. Mueller, and S. E. Mshana, "Predictors of triple therapy treatment failure among $\mathrm{H}$. pylori infected patients attending at a tertiary hospital in Northwest Tanzania: a prospective study," BMC Infectious Diseases, vol. 19, no. 1, p. 447, 2019.

[39] S. Rajper, E. Khan, Z. Ahmad, S. M. Z. Alam, A. Akbar, and R. Hasan, "Macrolide and fluoroquinolone resistance in Helicobacter pylori isolates: an experience at a tertiary care centre in Pakistan," Journal of the Pakistan Medical Association, vol. 62, no. 11, pp. 1140-1144, 2012.

[40] J. M. Kim, J. S. Kim, N. Kim et al., "Gene mutations of 23S rRNA associated with clarithromycin resistance in Helicobacter pylori strains isolated from Korean patients," Journal of Microbiology and Biotechnology, vol. 18, no. 9, pp. 1584-1589, 2008.

[41] S. Agudo, G. Perez-Perez, T. Alarcon, and M. Lopez-Brea, "High prevalence of clarithromycin-resistant helicobacter pylori strains and risk factors associated with resistance in Madrid, Spain," Journal of Clinical Microbiology, vol. 48, no. 10, pp. 3703-3707, 2010. 
[42] Q. Hao, Y. Li, Z. Zhang, Y. Liu, and H. Gao, "New mutation points in 23S rRNA gene associated with Helicobacter pylori resistance to clarithromycin in northeast China," World Journal of Gastroenterology, vol. 10, no. 7, p. 1075, 2004.

[43] I. Thung, H. Aramin, V. Vavinskaya et al., "Review article: The global emergence of Helicobacter pylori antibiotic resistance," Alimentary Pharmacology \& Therapeutics, vol. 43, no. 4, pp. 514533, 2016.

[44] N. F. Tanih and R. N. Ndip, "Molecular detection of antibiotic resistance in South African isolates of Helicobacter pylori," Gastroenterology Research and Practice, vol. 2013, 2013.

[45] F. Bazzoli, A. Gasbarrini, J. Atherton et al., "Management of helicobacter pylori infection-the Maastricht V/Florence consensus report," 2016.

[46] K. Aoki, P. E. Kihaile, M. Castro, M. Disla, T. B. Nyambo, and J. Misumi, "Seroprevalences of Helicobacter pylori infection and chronic atrophic gastritis in the united Republic of Tanzania and the Dominican Republic," Environmental Health and Preventive Medicine, vol. 9, no. 4, pp. 170-175, 2004.

[47] O. Secka, D. E. Berg, M. Antonio et al., "Antimicrobial susceptibility and resistance patterns among Helicobacter pylori strains from The Gambia, West Africa," Antimicrobial Agents and Chemotherapy, vol. 57, no. 3, pp. 1231-1237, 2013.

[48] S. N. Taylor, D. H. Morris, A. K. Avery et al., "Gepotidacin for the treatment of uncomplicated urogenital gonorrhea: a phase 2, randomized, dose-ranging, single-oral dose evaluation," Clinical Infectious Diseases, vol. 67, no. 4, pp. 504-512, 2018.

[49] H. Gressmann, B. Linz, R. Ghai et al., "Gain and loss of multiple genes during the evolution of Helicobacter pylori," PLoS Genetics, vol. 1, no. 4, article e43, 2005. 


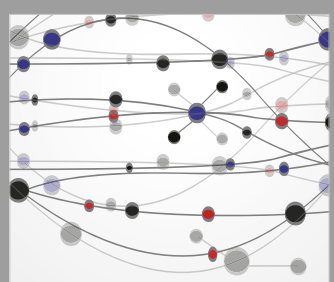

The Scientific World Journal
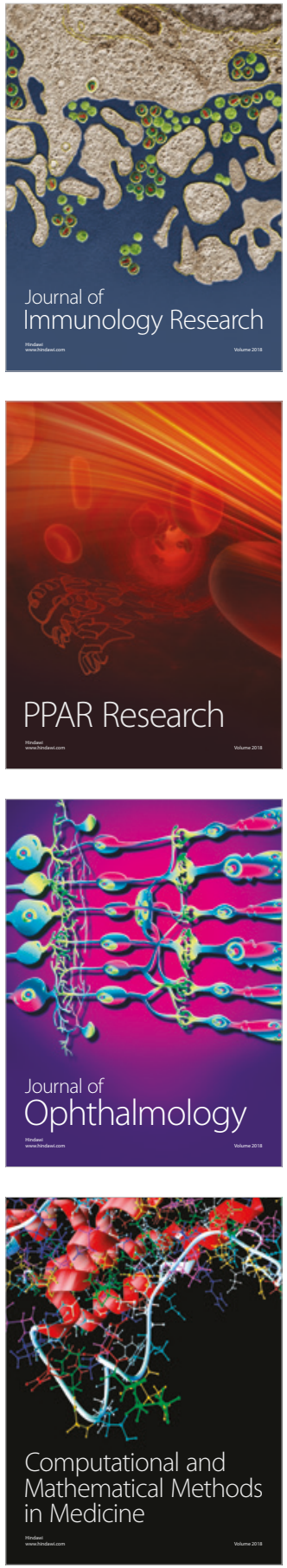

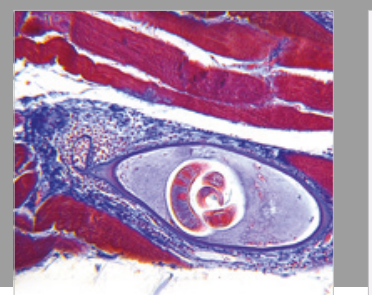

Gastroenterology Research and Practice

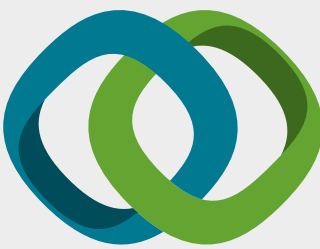

\section{Hindawi}

Submit your manuscripts at

www.hindawi.com
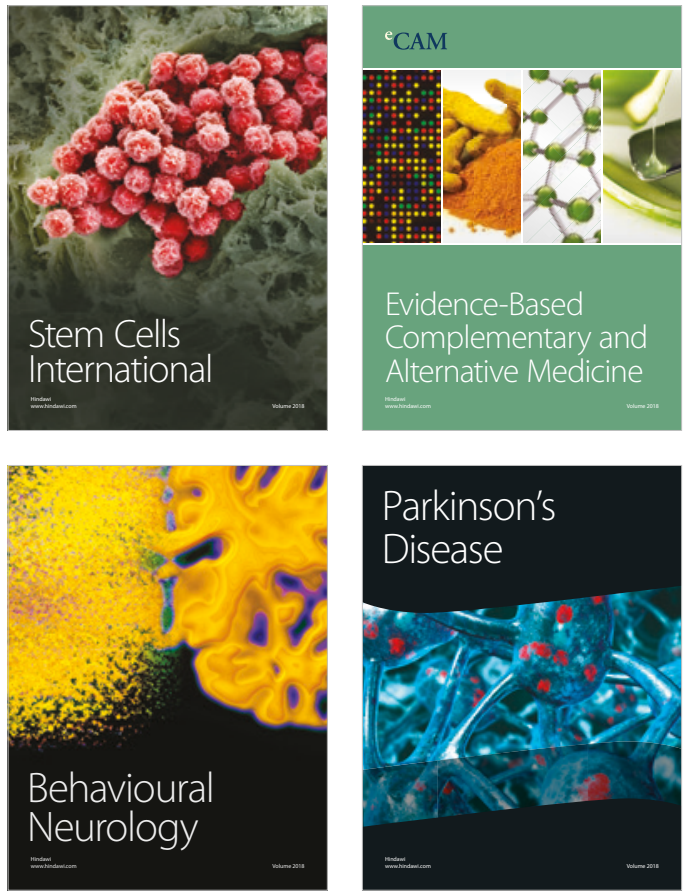

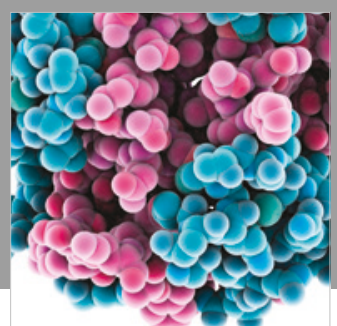

ournal of

Diabetes Research

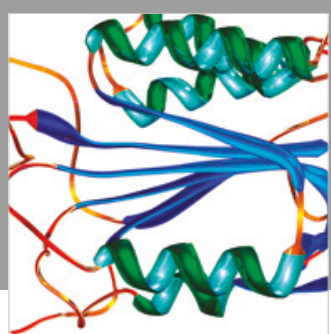

Disease Markers
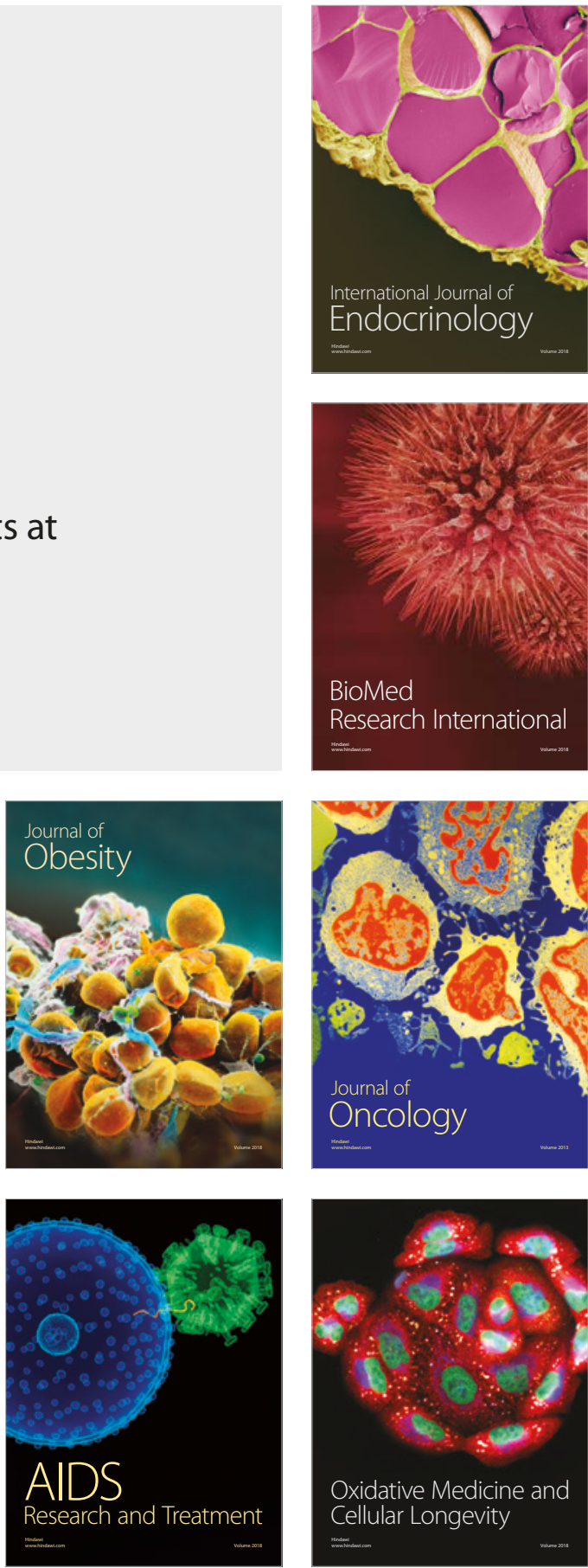